The Current Density in the Crater of the Carbon Arc

This content has been downloaded from IOPscience. Please scroll down to see the full text. 1920 Proc. Phys. Soc. London 3362

(http://iopscience.iop.org/1478-7814/33/1/307)

View the table of contents for this issue, or go to the journal homepage for more

Download details:

IP Address: 142.66.3.42

This content was downloaded on 07/09/2015 at 10:13

Please note that terms and conditions apply. 
VI.-The Current Density in the Crater of the Carbon Arc. $B y$ N. A. AlIEN, B.Sc.

RECEIVED MAY 27, 1920.

(Communicated By D. OWeN, B.A., D.Sc.)

ABstract.

In this work the $\mathrm{Y}$-arrangement of carbons due to Forrest was used. This facilitated accurate measurement of crater area. The carbons used were solid special electra of diameter $6 \mathrm{~mm}$. For currents up to 10 amperes the crater area was directly proportional to total current, thus maintaining a constant current density. This was 0.746 ampere per square millimetre.

THE object of the present research is an attempt to eliminate the uncertainty attending an investigation of the crater area, and the current density in the crater, of the carbon arc.

Mrs. Ayrton* found that a straight line law approximately connects crater area and current, but did not form any equation expressing the law, on account of possible errors in her measurements.

\begin{tabular}{|c|c|c|c|c|c|c|c|}
\hline \multicolumn{3}{|c|}{ Current in amperes. } & 4 & 7 & 10 & 15 & 20 \\
\hline \multirow{8}{*}{$\begin{array}{l}\text { Projected } \\
\text { are } \\
\text { lengths } \\
\text { in } \\
\mathrm{mm} .\end{array}$} & \multirow{2}{*}{1} & Ayrton ............. & $7 \cdot 56$ & 13.85 & $14 \cdot 2$ & $23 \cdot 3$ & $32 \cdot 2$ \\
\hline & & Rasch \& Tornberg & $7 \cdot 74$ & $12 \cdot 25$ & $16 \cdot 55$ & $23 \cdot 76$ & 30.97 \\
\hline & \multirow{2}{*}{2} & Ayrton ............. & $11 \cdot 35$ & 13.85 & $17 \cdot 7$ & $24 \cdot 6$ & $32 \cdot 2$ \\
\hline & & R. \& T........... & $9 \cdot 19$ & $13 \cdot 66$ & 17.95 & $25 \cdot 25$ & $32 \cdot 47$ \\
\hline & \multirow{2}{*}{3} & Ayrton ............. & $9 \cdot 89$ & $13 \cdot 85$ & - & $22 \cdot 5$ & $32 \cdot 2$ \\
\hline & & R. \& T............ & 9.9 & $14 \cdot 39$ & $18 \cdot 7$ & $25 \cdot 88$ & 33.08 \\
\hline & \multirow{2}{*}{4} & Ayrton ............ & 9.89 & $16 \cdot 65$ & 18.9 & $26 \cdot 4$ & $34 \cdot 2$ \\
\hline & & R. \& T. ........... & $10 \cdot 35$ & 14.86 & $19 \cdot 17$ & $26 \cdot 42$ & 33.59 \\
\hline
\end{tabular}

Rasch and Tornberg† obtained similar results to those of Mrs. Ayrton, and the two series of measurements are tabulated below, areas in square millimetres.

Mrs. Ayrton used cored positives, Rasch cored negatives.

The lines representing these figures approximately, are shown in Fig. 3, for comparison with the results of the present work, which was done with arc lengths of 1 to $10 \mathrm{~mm}$., the arc being always perfectly silent. Solid carbons were used.

* "The Electric Are," p. 151, et seg.

$\dagger$ "Electric Arc Phenomena," p. 143, et se?. 
The chief difficulties met in a measurement of crater area are as follows :-

1. The crater cannot be viewed directly.

2. The area must be calculated from an oblique measurement of crater diameter, assuming the crater to be truly circular, which is by no means certain.

3. The edges of the crater may not be well defined.

4. The crater is curved inwards, so that the true area is greater than that observed.

5 . The presence of fumes and carbon vapour in the crater may cause error due to refraction.

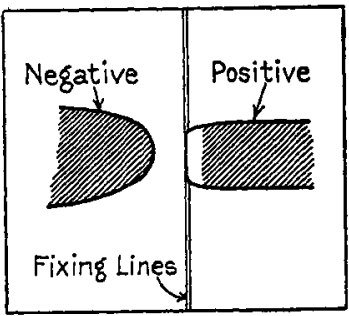

Front View of Screen B.
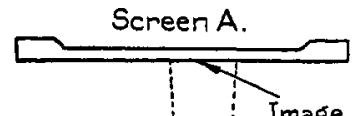

Image

Sereen $B$.

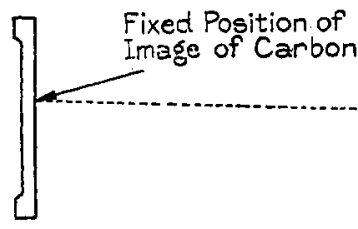

Fixed Position of

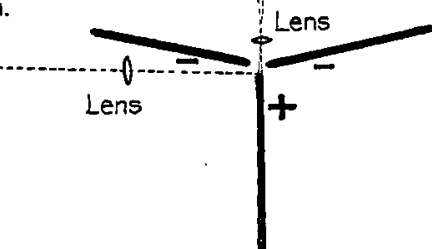

FIG. 1

The last two difficulties disappear if apparent crater area is required, as in photometric work. None of these causes of inaccurate results, however, are found with the Y-arrangement of carbons originated by Forrest,* and used in the present work.

Messrs. Paterson, Walsh, Taylor and Barnett $\dagger$ assumed that the positive crater covers the whole of the end of the carbon *" Electrician," 1913, Vol. LXXI., pp. 729 and 1007. +" Proc." Inst. El. Eng., Vol. LVIrI. 
for all currents when the current density in the actual carbon exceeds 0.2 amperes per square millimetre. Figures since communicated, however, show that for currents of 100 to 220 amperes the true density in the crater was sensibly constant, which agrees with the results of the present work, which was carried out with much smaller currents, the true density in their case being about $0.45 \mathrm{amp}$. per sq. $\mathrm{mm}$.

\section{Methods Adopted.}

The arc was always maintained absolutely silent, and before readings were taken, 10 or 15 minutes was always allowed for the carbons to burn to a steady condition. The current in each negative was kept about the same, but it was found

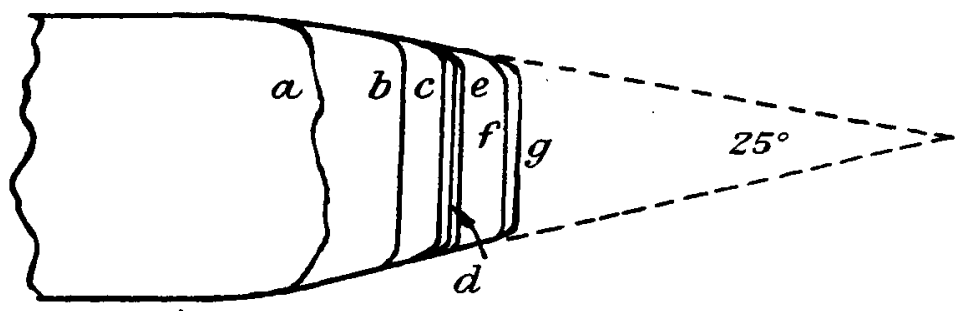

Fig. 2.-Tracing of Image of Positive Carbon.

(Magnification $=5.2$ times.)

Crater Face.

a. 12 ampere (unsteady, hissing violently).

b. $9 \cdot 0$ ampere.

c. $7 \cdot 0$ ampere.

d. $6 \cdot 5$ ampere.

e. 6.0 ampere.

f. 4.8 ampere.

g. $4 \cdot 5$ ampere.

that the positive crater was unchanged when one took 50 per cent. more current than the other. The arc length was that which gave perfect silence for any one current. An image of the positive crater was thrown on a screen, and the area was measured by making many points round the circumference with a fine pencil.

Since with the apparatus in use, an error of $1 \mathrm{~mm}$. backward or forward in the position of the positive crater would cause an 8 per cent. error in the area, the arrangement shown in Fig. 1 was devised. A screen $B$ was placed at the side of the arc, and an enlarged image of the positive carbon focussed upon it. Two fine lines were drawn on this screen parallel and vertical, and the end of the image must just show in between for the carbon to be correctly disposed. 
The magnification of the image on screen $A$ was measured by placing a series of cylindrical gauges having flat polished ends, with their faces in turn in the correct position, and measuring the image of the gauge when brilliantly illuminated.

Calibration of Magnification.

\begin{tabular}{|c|c|c|}
\hline Gauge. & Diameter in mm. & Magnification. \\
\hline 1 & $4 \cdot 782$ & $31 \cdot 72$ \\
2 & $3 \cdot 210$ & 31.49 \\
3 & $2 \cdot 739$ & $31 \cdot 73$ \\
4 & 1.680 & $31 \cdot 56$ \\
\hline
\end{tabular}

Distortion being thus negligible, the mean magnification of 31.62 was used.

Limits of Accuracy.

Possibility of inaccuracy was as follows:-

(a) Due to error in position of carbon, less than $0.1 \mathrm{~mm}$. causing area to be subject to an error of 0.75 per cent.

(b) Due to error in magnification; less than 0.1 per cent.

(c) Due to error in measuring image -0.6 per cent.

(d) Error in observing current -0.25 per cent.

Total error probably well within 1 per cent.

\section{Results (a) Shape of Carbon and Crater.}

The crater was always a true circle. It is suggested that this is due to the mutual attraction of parallel streams of current flowing in the same direction. It was found impossible to maintain two separate arcs on the end of the same positive.

A tracing was made at several currents of the projection of the positive carbon. This showed that in all cases when the arc has burned to a steady condition, the carbon tapers down uniformly at an angle of about $25 \mathrm{deg}$. (see Fig. 2), the crater occupying the whole of the reduced end of the carbon. The crater was flat and quite smooth, and perpendicular to the axis of the carbon, as evidenced:-

1. By the appearance of the carbon when examined, and

2. By the fact of the whole crater being in focus on the screen when projected. 
Results (b) Crater Area and Current Density.

On Fig. 3 are plotted all the observations made, and for comparison results by previous investigators are' given also.

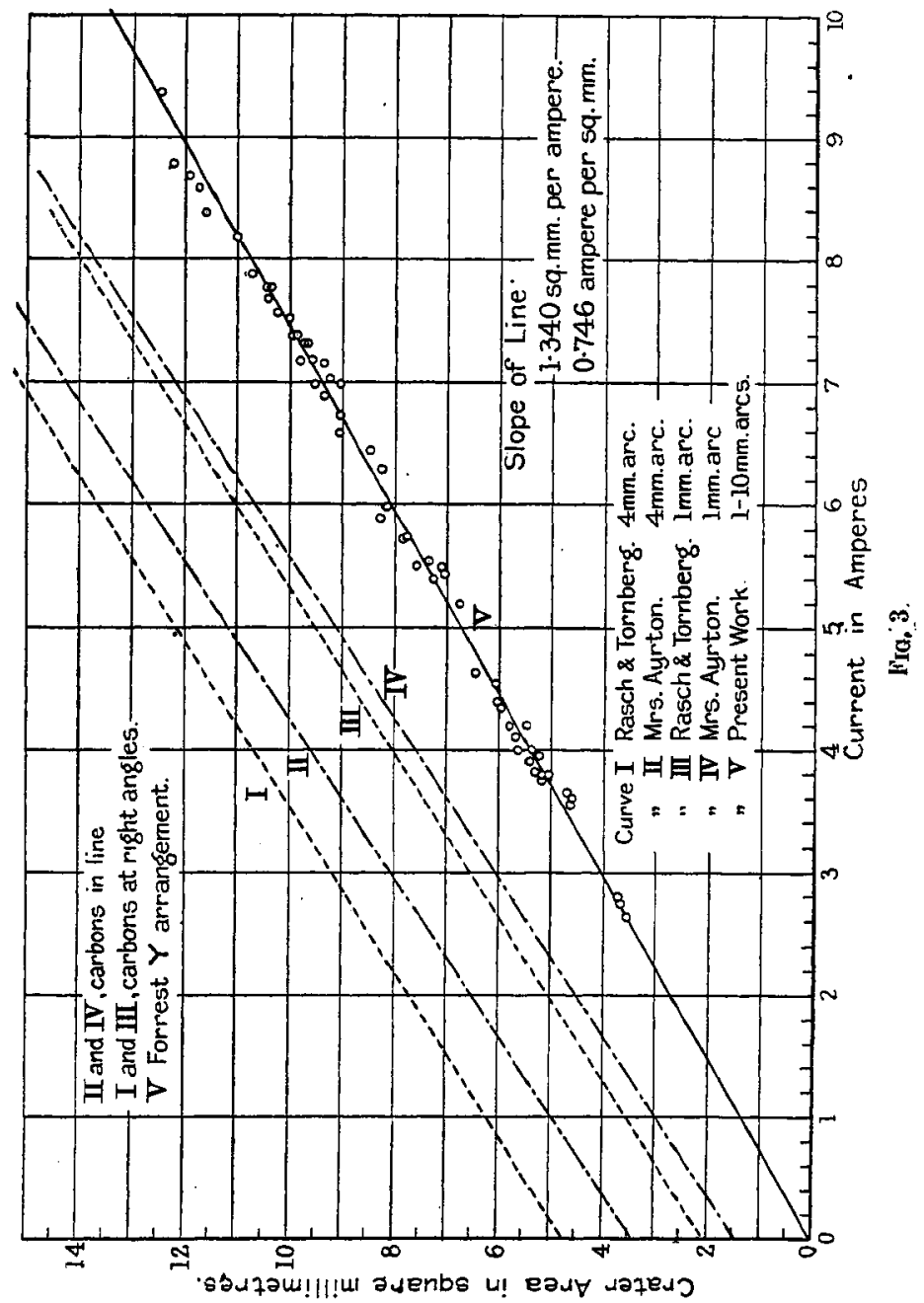

The current densities have been worked out for Fig. 4. The maximum deviation from the mean on any observation in a 
CURRENT DENSITY IN CARBON ARC.

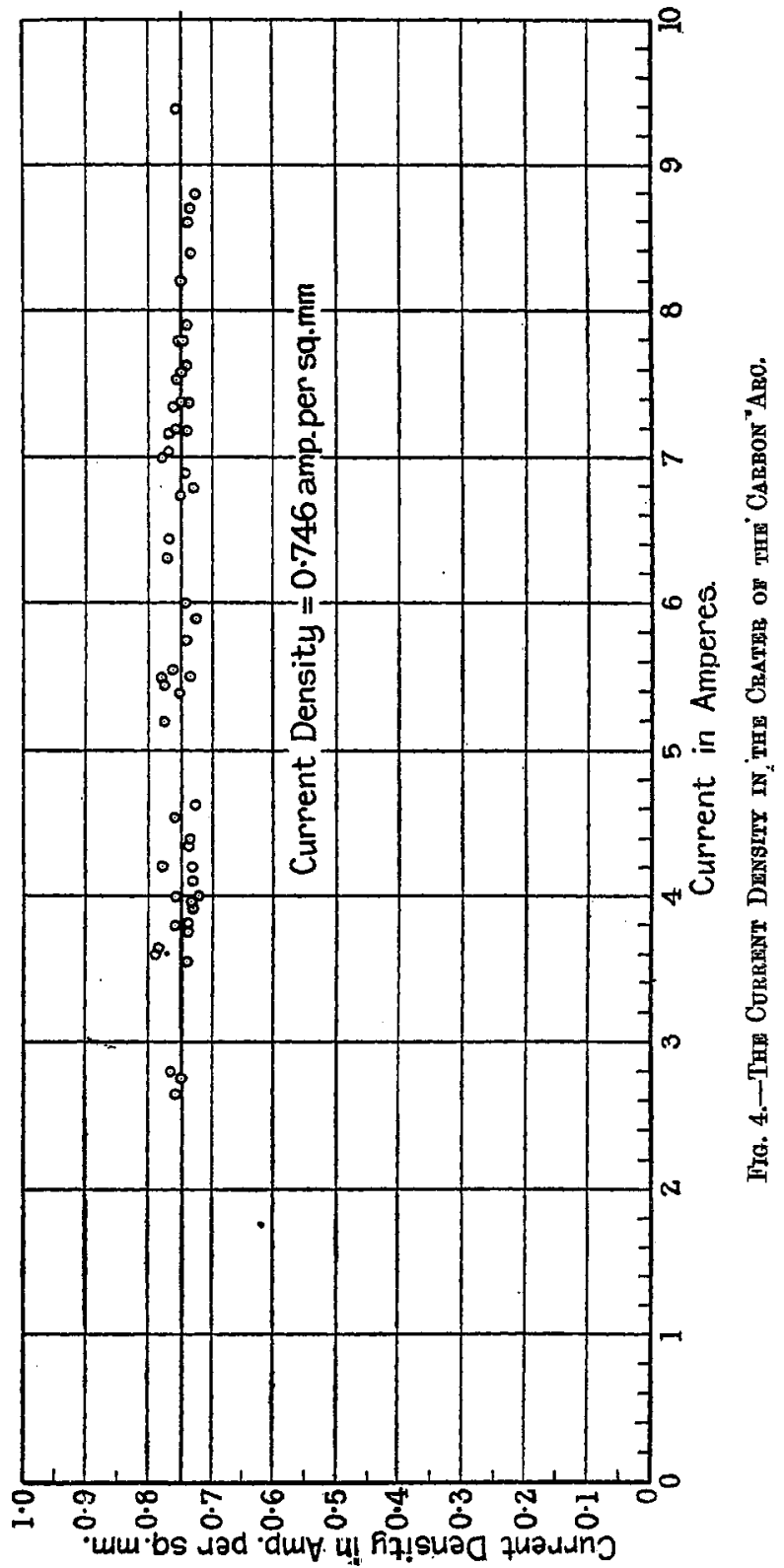


series of 60 readings of current density was only 5 per cent., and 70 per cent. of all results were within 2 per cent.

The carbons used were solid special electra carbons marked [-- - - - - ELECTRA] of diameter $6 \mathrm{~mm}$., and as a conclusion to the present research it may be stated that for currents up to 10 amperes, using the $Y$-arrangement of carbons :

(a) Crater area is directly proportional to total current, and

(b) The current density in the positive crater is a constant and, correct to 1 per cent., is equal to 0.746 amperes per square millimetre.

If $A=$ crater area in square millimetres,

$I=$ current in amperes,

then

$$
A=1 \cdot 340 I \text {. }
$$

This research was carried out in the Electrical Engineering Laboratory at the East London College, and the best thanks of the author are due to Prof. J. T. MacGregor-Morris for suggesting this line of investigation, and for some very helpful criticisms and suggestions during the work.

\section{DISCUSSION.}

Prof. MORRIs read a portion of a letter from Mrs. Ayrton, who considered the Paper of great importance, and that the results were what she would have expected from accurate determinations.

The speaker mentioned that the carbons used were very pure. The effect of quality of carbon on current density had to be investigated.

The late Mr. Forrest, of whose work this was a continuation, showed that the candle-power per square millimetre was 172 to 174 . Combining this result with that of the present Paper, we find that the candle-power per ampere is 232. He suggested, therefore, that the Y-type of arc gives a standard of light, requiring only an ammeter and good quality carbons, constant to at least 1 per cent.

Prof. RANKINE asked if the result was unaffected by the mass of carbon carrying off the heat.

Prof. MorkIs said the result was certainly true from 6 to 10 amperes.

Dr. BRyas asked how the result was affected by the presence of areas of special brightness or darkness. He had frequently noticed such areas.

Mr. F. J. W. WhIPPLE asked if Prof. Morris could give an idea of the physics of the constancy of current density.

Dr. D. Owns said he was going to refer to the same question. The crater was stated to be perfectly circular, and the edge was very sharp, judging from the photograph shown on the screen. This was surprising. One would have expected some sort of penumbral region. A comparison of the ionic conditions in the arc with those in a conducting liquid was of interest. $n e u=$ constant where $n$ is the number of charged particles per unit volume, $e$ the charge on each, and $u$ their velocity. In the arc, as the current increases the voltage diminishes, and therefore the velocity $u$ decreases. Consequently $n$ must increase. In the case of electrolytic conduction $n$ is constant. 
Mr. J.W.T. WALSH (communicated) : I much regret that another engagement prevents my being present when Mr. Allen's very interesting and valuable Paper is read.

The results obtained are most surprising in their regularity and the accuracy with which the crater area remains proportional to the current. for all the arc lengths employed. The current density found is much higher than that generally recognised hitherto as the limits of steady burning for arcs of large currents, say, from 100 to 200 amperes. It would be most valuable if the author could see his way to extending his researches to include ourrents of such magnitude as this. The work done at the National Physical Laboratory was practically confined to large current arcs, and the difficulties experienced in obtaining steady burning conditions with these show that the smaller current arcs behave much more regularly, and are, therefore, probably capable of smooth running at much higher current densities than the larger arcs. In this connection I should like to express my thanks to Prof. Morris, who very kindly gave me an opportunity of seeing Mr. Allen's apparatus working at East London College. The smoothness of running of the are, and the uniformity of brightness of the crater were remarkable and $I$ feel sure that everyone who has worked on the carbon arc will be more than interested in the results presented this evening, and will look forward to further work by the author on similar lines.

The AUTHor communicated the following: In reply to Prof. Rankine, the carbons used were all the same size--6 $\mathrm{mm}$. diameter.

The effects mentioned by Dr. Bryan, which are due to inequalities in the carbons, do not affect the results, as when a bright or dark area is present the arc is unsteady, and one has been careful to avoid taking readings under unstable conditions.

Dr. Owen assumed that as the current increases the voltage diminishes. This is true when the length of the arc is kept constant, but in the case of these silent arcs, length is approximately proportional to current, hence as the current increases, the voltage remains fairly constant. Then in the equation used by Dr. Owen ( $n e u=$ const.), since the voltage is constant, therefore the velocity is constant, hence the number of ions or charged particles is constant.

Another interesting result following from the relation between current and length for silence is as follows: Mrs. Ayrton ("Electric Arc," p. 158) suggested that the equation connecting arc current and area was

If $L=\gamma I$,

$$
A=\alpha L+\beta I . \quad(A=\text { area, } L=\text { length, } I=\text { current. })
$$

then $A=$ constant $\times I$, as the present work shows.

Yr. Walsl mentions that the current density obtained was higher than he would have expected. This high current density appears to be due largely to the reactions of the arc streams upon each other, forcing up the current density to a high value. 